\title{
BMJ Open Workplace violence, psychological stress, sleep quality and subjective health in Chinese doctors: a large cross- sectional study
}

Tao Sun, ${ }^{1}$ Lei Gao, ${ }^{1}$ Fujun Li, ${ }^{2}$ Yu Shi, ${ }^{1}$ Fengzhe Xie, ${ }^{1}$ Jinghui Wang, ${ }^{1}$ Shuo Wang, ${ }^{3}$ Shue Zhang, ${ }^{4}$ Wenhui Liu, ${ }^{1}$ Xiaojian Duan, ${ }^{1}$ Xinyan Liu, ${ }^{1}$ Zhong Zhang, ${ }^{1} \mathrm{Li} \mathrm{Li},{ }^{1}$ Lihua Fan ${ }^{1}$

To cite: Sun T, Gao L, Li F, et al. Workplace violence, psychological stress, sleep quality and subjective health in Chinese doctors: a large crosssectional study. BMJ Open 2017;7:e017182. doi:10.1136/ bmjopen-2017-017182

- Prepublication history for this paper is available online. To view please visit the journal online (http://dx.doi.org/10. 1136/bmjopen-2017-017182).

TS, LG and FL contributed equally.

Received 7 April 2017 Revised 16 August 2017 Accepted 17 August 2017

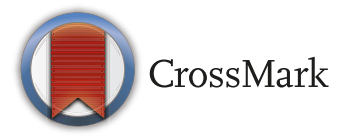

${ }^{1}$ Department of Health Management, School of Public Health, Harbin Medical University, Harbin, China 2Department of Anesthesiology, The First Affiliated Hospital of Harbin Medical University, Harbin, China

${ }^{3}$ Department of Out-Patient Office, The Second Affiliated Hospital of Harbin Medical University, Harbin, China ${ }^{4}$ Department of Pharmacy, The Third Affiliated Hospital of Harbin Medical University, Harbin, China

\section{Correspondence to}

Professor Li Li; healthlaw@126.com and

Prof. Lihua Fan;

lihuafan@126.com

\section{ABSTRACT}

Background Workplace violence (WPV) against healthcare workers is known as violence in healthcare settings and referring to the violent acts that are directed towards doctors, nurses or other healthcare staff at work or on duty. Moreover, WPV can cause a large number of adverse outcomes. However, there is not enough evidence to test the link between exposure to WPV against doctors, psychological stress, sleep quality and health status in China.

Objectives This study had three objectives: (1) to identify the incidence rate of WPV against doctors under a new classification, (2) to examine the association between exposure to WPV, psychological stress, sleep quality and subjective health of Chinese doctors and (3) to verify the partial mediating role of psychological stress.

Design A cross-sectional online survey study.

Setting The survey was conducted among 1740 doctors in tertiary hospitals, 733 in secondary hospital and 139 in primary hospital across 30 provinces of China.

Participants A total of 3016 participants were invited. Ultimately, 2617 doctors completed valid questionnaires. The effective response rate was $86.8 \%$.

Results The results demonstrated that the prevalence rate of exposure to verbal abuse was the highest (76.2\%), made difficulties (58.3\%), smear reputation (40.8\%), mobbing behaviour (40.2\%), intimidation behaviour (27.6\%), physical violence $(24.1 \%)$ and sexual harassment (7.8\%). Exposure to WPV significantly affected the psychological stress, sleep quality and self-reported health of doctors. Moreover, psychological stress partially mediated the relationship between work-related violence and health damage.

Conclusion In China, most doctors have encountered various WPV from patients and their relatives. The prevalence of three new types of WPV have been investigated in our study, which have been rarely mentioned in past research. A safer work environment for Chinese healthcare workers needs to be provided to minimise health threats, which is a top priority for both government and society.

\section{INTRODUCTION}

A decade ago, China's government launched a new round of health system reforms. So far, the medical care insurance system and public
Strengths and limitations of this study

- The prevalence of three new accessorial types of workplace violence is conducted in this study, with high response rates.

- This is the first study investigating the relationship between workplace violence and psychological stress, sleep quality and self-reported health of doctors in China.

- The finding that psychological stress partially mediated the relationship between work-related violence and health damage is first reported.

- The approach to self-reports of doctors in an online survey may lead to response bias.

- The results of the study are not generalisable to all Chinese doctors.

health system have been built. In addition, more attention has been paid to the development of primary health services. ${ }^{1}$ Although these reforms have achieved much in China, it is still difficult for residents to get medical services, and healthcare costs have been rising exponentially. ${ }^{1}$ More importantly, Chinese doctors and patients both do not feel that they have profited from the previous series of reforms. On the contrary, the doctor-patient relationship seems to have been deteriorating lately. $^{2}$

In China, the human resources for health are seriously insufficient, and inequalities exist at the same time. ${ }^{3}$ Moreover, there is an imbalance in the resources' structure. For example, the highest quality of health resources are concentrated in large cities, whereas Chinese primary healthcare is still very weak. ${ }^{4}$ As a consequence, people tend to flock to public tertiary general hospitals. Unfortunately, the current medical care insurance system cannot relieve the catastrophic health expenditure, ${ }^{5}$ and residents 
often complain about high medical costs. Along with the factors social change, incompetent medical education and lack of professionalism in medical staff, most doctors are only busy with aspects of technical problems; all of which result in a lack of awareness at the humanistic level during the process of service. ${ }^{6}$ This is an important reason why the doctor-patient relationship is not harmonious in China. ${ }^{7}$ Owing to the price of medical services and technology and income under strictly government-controlled conditions, there is an unreasonable phenomenon where doctors' benefits from medical technology are very low in China. Contrary to what the government wishes, in order to make a profit, some Chinese doctors try to provide unreasonable prescriptions for the patients to earn more money ${ }^{8}$; some often communicating unlawfully with drug/medical appliance dealers. Naturally, the Chinese government attaches much importance to this problem, and many relevant policies have been introduced to solve these issues. Regardless, this phenomenon has caused a large number of adverse effects. Doctor-patient relationships are becoming more and more fragile in China, ${ }^{7}$ and most patients already do not trust doctors, including all other healthcare staff. In recent years, many doctors have been assaulted, seriously injured and even murdered by patients or visitors in China. Consequently, doctors are at high risk of serious injury or death in hospital settings caused by attacks from patients. Workplace violence (WPV) against doctors has already become a public health issue and a very common phenomenon in China. ${ }^{9}$ Unfortunately, the reports of these incidents by the media have further exacerbated the conflict between doctors and patients. ${ }^{10}$ Therefore, the occupational safety of Chinese doctors has come to a very grave juncture.

\section{BACKGROUND}

WPV against healthcare workers is known as violence in healthcare settings, including the violent acts that are directed towards doctors, nurses or other healthcare staff at work or on duty. ${ }^{11}$ According to a survey, the prevalence of violence against emergency physicians in Morocco was $70 \%,{ }^{12}$ in South Africa the proportion of personnel that had encountered violence rose to $61 \%$ and in Thailand, $54 \% .{ }^{13}$ In Jordan, a survey of nurses in the emergency department showed that $75 \%$ of emergency had experienced violence, among which verbal violence was the most common phenomenon, accounting for $63.9 \%$, and physical violence accounted for $48 \% .{ }^{14}$ It has become an increasingly serious public health problem worldwide but is more common in China ${ }^{15}$ and has attracted considerable attention and global discussion. ${ }^{16}$ It is noteworthy that in recent years, WPV has become rampant and is an extensive problem in Chinese healthcare settings. However, it is also an ubiquitous, under-reported and persistent problem that has been tolerated and largely ignored. ${ }^{17}$ Since 2002 in China, there is growing evidence that the incidence rate of WPV in healthcare settings has been increasing annually ${ }^{18}$ and that the number of incidents of serious violence towards doctors is growing rapidly. ${ }^{19}$ These findings demonstrate that China's doctors are facing a severe threat to occupational safety. Furthermore, previous studies indicated that exposure to WPV in healthcare settings could lead to adverse consequences for health professionals, such as a decline in job performance, ${ }^{20}$ increased turnover intentions and reduced job satisfaction, ${ }^{21}$ greater stress and burnout, ${ }^{22}$ low quality of life ${ }^{23}$ and so on. Moreover, exposure to violence has a negative effect on the health of hospital staff, ${ }^{24}$ and due to the rise of occupational stress, their family life and quality of life are affected as well. ${ }^{25}$

Research on WPV in healthcare settings has been widely carried out and revealed antecedent and consequence variables in many previous studies. ${ }^{26}{ }^{27}$ However, most research focused only on physical or psychological violence, the two types of violence that represent only the tip of the iceberg. Classically, WPV is defined by the WHO as 'the intentional use of physical force or power, threatened or actual, against oneself, another person, or against a group or community, that either results in or has a high likelihood of resulting in injury, death, psychological harm, maldevelopment, or deprivation. ${ }^{28}$ According to this definition, obscure WPV tends to cause psychological harm, maldevelopment or deprivation in the practices of Chinese healthcare workers. A number of studies already reported about non-physical violence against healthcare workers and its effects. ${ }^{29}{ }^{30}$ Surprisingly, these types of violence were not considered in previous Chinese investigations. Thus, a wider range of types should be discussed for violence against healthcare workers.

Still, it is generally known that WPV can cause a large number of adverse outcomes, which have been verified widely, including personal, organisational and social-level outcomes. However, there is not enough evidence to test the link between exposure to WPV against doctors, psychological stress, sleep quality and health status in China.

This study aims to identify the incidence rate of WPV against doctors under a new classification by conducting a cross-sectional online survey; to examine the association between exposure to WPV, psychological stress, sleep quality and subjective health of Chinese doctors; and verify the partial mediating role of psychological stress.

\section{METHODS \\ Subjects and procedures}

An anonymous online questionnaire was completed by doctors throughout the country during May 2016 in China. This cross-sectional study was conducted across 30 provinces of China. First, approximately 50 doctors from the authors' unit were selected as the original deliverers of the survey. Subsequently, the colleagues or classmates of 'the original deliverers' were invited to participate in our online survey. A web page link to our questionnaire survey (https://www.wenjuan.com/) was sent by mobile phone to subjects during doctors' rest 
breaks. Moreover, the questionnaires were self-administered. A total of 3016 participants were invited in this survey. Ultimately, 2617 valid questionnaires were used in the final data analysis. The effective response rate was $86.8 \%$.

The research described in this article meets the guidelines of the Ethics Committee of the College of Public Health, Harbin Medical University, and the project has been approved by the Ethics Committee of the Harbin Medical University (ECHMU). Written informed consent could not be received due to the anonymous survey approach. Hence, oral informed consent for the survey was approved by the ECHMU and obtained from each doctor. Once a questionnaire was completed, it was identified that the doctor has orally agreed to participate in our survey by reference to the Wen's criteria. ${ }^{19}$

\section{Measures}

Measurement of the WPV against doctors

This study used a new measurement tool developed by Zhang to assess the prevalence of WPV. ${ }^{31}$ Under the new classification, WPV was divided into seven dimensions, including verbal violence (abuse, sarcasm, indignity, effrontery, roar and so on), made difficulties (nit-picking demands, unreasonable requests, non-compliance, heckling and so on), smear reputation (baseless charges or complaints, slander, impudence for damaging reputation and so on), mobbing behaviour (destruction of public facilities, booing, gather together to stir up trouble, public disorder, malicious camera shooting and so on), intimidation behaviour (oral or written threats, glower, waving a clenched fist, threatening with weapons, stalking and so on), physical violence (biting, pushing, fighting, cutting, throwing things towards body and so on) and sexual harassment (also including rape or attempts to rape). Until now, made difficulties, smear repuztation and mobbing behaviour had been seriously neglected in previous studies. On the contrary, these behaviours very commonly trouble Chinese doctors at work, and exposure to such violence may lead to a great stress for doctors and threaten their well-being. Most importantly, these mistreatment behaviours completely meet the standards for the definition and scope of WPV.

In the present survey, we used a 6-point Likert scale, with 'never', rarely', 'occasionally', 'often', 'frequently' and 'every day', to reflect the frequencies of work-related violence against doctors. At the time of questionnaire coding, 'never' and 'rarely' were regarded as non-experience of WPV from patients or their relatives. Thus, they were assigned a score of ' 0 '. Other situations were assigned a score of ' 1 ', signifying that these doctors have encountered this type of violence during the past year. The Cronbach's alpha for the scale was 0.885 in this survey.
Measurement of psychological stress, sleep quality and subjective health

With reference to previous research, psychological stress ${ }^{24}$ was used as an item to measure the perceived pressure of doctors, rated on a 5-point Likert scale, ranging from 1 to 5 ( $1=$ not at all, 5 =verymuch). Two single items were addressed together to measure doctors' self-reported health outcomes (sleep quality and subjective health). Subjective sleep quality ${ }^{32}$ was measured by using one item, namely, 'How would you evaluate this night's sleep?', the response format for which ranged from very bad (1) to very good (4). Additionally, our study consulted the research of Fein and Skinner ${ }^{33}$ and estimated overall subjective health by a widely used single-item measure ('In general, would you say your health is verygood, good, poor, very poor').

Moreover, this study also captured several demographic details of participants, such as: gender, age, service years, hospital level, marital status, educational categories and so on.

\section{Statistical analysis}

Demographic characteristics of the respondents were collected to report sample information. Pearson's correlation coefficients were calculated to estimate correlations between the exposure to WPV, psychological stress, sleep quality and self-subjective health. Multiple hierarchical linear regression analysis was performed to test the effects of groups of independent variables on dependent variables. The demographic variables related to WPV in univariate analysis $(p<0.05)$ were entered into step 1 of the hierarchical regression analysis model to eliminate their interference on the dependent variables. A series of regression analyses were performed to examine our hypotheses according to a procedure that was suggested by Baron and Kenny. ${ }^{34}$ The Sobel Test was used in mediation analysis by adopting Preacher's test programme. ${ }^{35}$ We provided data including $F, \mathbf{R}^{2}$ and $\mathbf{R}^{2}$-changes, and the fit of the model was assessed with $R^{2}$. Standardisation regression coefficients $(\beta)$ and $p$ values were calculated for each step in the regression model. In this study, statistical significance was set at $\mathrm{p}<0.05$ (two tailed). All of the above analyses were conducted using SPSS V.13.0 for Windows.

\section{RESULTS}

\section{Demographic characteristics of the respondents}

A summary of demographic variables can be seen in table 1 .

\section{Prevalence of different styles of WPV against doctors}

As shown in table 2, about $76.2 \%$ of participants reported having encountered verbal violence within the last 12 months, which is the highest incidence rate among all kinds of WPV in hospitals. Other incidence rates of WPV from highest to lowest are: made difficulties (58.3\%), smear reputation (40.8\%), mobbing behaviour (40.2\%), intimidation behaviour $(27.6 \%)$, physical violence $(24.1 \%)$ and sexual harassment $(7.8 \%)$. 
Table 1 Characteristics of the respondents $(n=2617)$

\begin{tabular}{lrr}
\hline Characteristic & N & $\%$ \\
\hline Age (years) & & \\
$20-30$ & 587 & 22.4 \\
$31-40$ & 1224 & 46.8 \\
$41-50$ & 658 & 25.1 \\
$51+$ & 119 & 4.5 \\
Missing value & 29 & 1.1
\end{tabular}

Service years

$\begin{array}{lrr}0-10 & 1088 & 41.6 \\ 11-20 & 720 & 27.5 \\ 30+ & 376 & 14.4 \\ \text { Missing value } & 433 & 16.5\end{array}$

Hospital level

\begin{tabular}{lrr} 
Tertiary hospitals & 1740 & 66.6 \\
\hline Secondary hospital & 733 & 28.1 \\
\hline Primary hospital & 139 & 5.3 \\
\hline Missing value & 5 & 0.2 \\
Gender & & \\
$\quad$ Male & 1240 & 47.4 \\
\hline Female & 1369 & 52.3 \\
\hline Missing value & 8 & 0.3 \\
Education & & \\
College degree or below & 291 & 11.1 \\
\hline Bachelor & 1350 & 51.7 \\
\hline Master & 692 & 26.5 \\
\hline Doctor & 277 & 10.6 \\
\hline Missing value & 7 & 0.3 \\
Marital status & & \\
\hline Unmarried & 397 & 15.2 \\
\hline Married & 2148 & 82.1 \\
\hline Divorced or loss of spouse & 70 & 2.7 \\
\hline Missing value & 2 & 0.1 \\
\hline
\end{tabular}

Professional categories

\begin{tabular}{|rrr|}
\hline Without professional title & 306 & 11.7 \\
\hline Resident doctor & 564 & 21.6 \\
\hline Attending physician & 898 & 34.3 \\
\hline Associate chief physician & 569 & 21.7 \\
\hline Chief physician & 270 & 10.3 \\
\hline Missing value & 10 & 0.4 \\
\hline Shift work & & \\
$\quad$ Often work during the day & 503 & 19.2 \\
\hline Occasional work at night & 500 & 19.1 \\
\hline Often work at night & 1613 & 61.6 \\
\hline Missing value & 1 & 0.1 \\
\hline Working time (hour) & & \\
\hline 0-8 & 528 & 20.2 \\
\hline
\end{tabular}

\begin{tabular}{lrr} 
Table 1 Continued & & \\
\hline Characteristic & N & \multicolumn{1}{l}{$\%$} \\
\hline $9-10$ & 1297 & 49.6 \\
$11-12$ & 504 & 19.2 \\
$13+$ & 285 & 10.9 \\
Missing value & 3 & 0.1 \\
\hline
\end{tabular}

Incidence rate of accumulated types of expose to WPV against doctors

As shown in table 3, $83.4 \%$ of participants reported having experienced one or more types of WPV during the last 12 months, which indicates that the prevalence of WPV against doctors in China is $83.4 \%$. Furthermore, $18.8 \%$ of participants reported having suffered one type of violence, $14.9 \%$ of participants reported having encountered two types of violence, $14.1 \%$ of participants reported having experienced three types of violence, $11.7 \%$ of participants reported having suffered four types of violence, $9.8 \%$ of participants reported having suffered five types of violence, $10.0 \%$ of participants reported having suffered six types of violence and $4.0 \%$ of participants reported having suffered seven types of violence.

\section{Correlations between study variables}

The means, SDs and Pearson correlation coefficients of continuous variables are shown in table 4. As the results demonstrate, all variables were significantly correlated with each other. WPV was positively correlated with psychological stress $(\mathrm{r}=0.382, \mathrm{p}<0.001)$ and negatively associated with subjective sleep quality $(r=-0.281$, $\mathrm{p}<0.001)$ and subjective health $(\mathrm{r}=-0.471, \mathrm{p}<0.001)$. Psychological stress was negatively related to subjective sleep quality $(\mathrm{r}=-0.281, \mathrm{p}<0.001)$ and subjective health $(\mathrm{r}=-0.464, \mathrm{p}<0.001)$.

\section{Multiple hierarchical linear regression models of study variables}

To evaluate the association between the exposure to WPV, psychological stress, sleep quality and health status of doctors, we relied on the three-step mediated regression approach that Baron and Kenny ${ }^{34}$ recommend. Results of mediation analysis are shown in table 5 and illustrated

Table 2 The incidence rate and rank ordering of WPV against doctors within last 12 months

\begin{tabular}{lllll}
\hline Violence styles & N & $\%$ & Total & Rank \\
\hline Verbal violence & 1993 & 76.2 & 2616 & 1 \\
Made difficulties & 1527 & 58.3 & 2616 & 2 \\
Smear reputation & 1068 & 40.8 & 2615 & 3 \\
Mobbing behaviour & 1051 & 40.2 & 2615 & 4 \\
Intimidation behaviour & 721 & 27.6 & 2616 & 5 \\
Physical violence & 631 & 24.1 & 2614 & 6 \\
Sexual harassment & 203 & 7.8 & 2615 & 7 \\
\hline
\end{tabular}

WPV, workplace violence. 
Table 3 Incidence rate of accumulated types of WPV against doctors within the last 12 months

\begin{tabular}{llrrc}
\hline $\begin{array}{l}\text { Accumulated } \\
\text { violence }\end{array}$ & N & \multicolumn{1}{c}{$\%$} & $\begin{array}{l}\text { Valid per } \\
\text { cent }\end{array}$ & $\begin{array}{l}\text { Cumulative } \\
\text { percentages }\end{array}$ \\
\hline 0 & 433 & 16.5 & 16.6 & 16.6 \\
One type & 491 & 18.8 & 18.8 & 35.4 \\
Two types & 389 & 14.9 & 14.9 & 50.3 \\
Three types & 370 & 14.1 & 14.2 & 64.4 \\
Four types & 305 & 11.7 & 11.7 & 76.1 \\
\hline Five types & 256 & 9.8 & 9.8 & 85.9 \\
\hline Six types & 263 & 10.0 & 10.1 & 96.0 \\
\hline Seven types & 105 & 4.0 & 4.0 & 100.0 \\
\hline
\end{tabular}

WPV, workplace violence.

that psychological stress is a partial mediator in the relationship between violence and sleep quality. Moreover, psychological stress also partially mediated the relationship between violence and subjective health.

\section{DISCUSSION}

\section{New styles and prevalence of WPV against doctors in China}

This study discovered that the incidence rate of WPV against Chinese doctors was $83.4 \%$, similar to previous reports. ${ }^{36}$ Of all participants in this survey, most have encountered and been victims of at least two styles of violence in the last 12 months. Specifically, exposure to verbal violence was most frequently reported by Chinese doctors with a rate of $76.2 \%$. This result is consistent with previous studies. ${ }^{36}{ }^{37}$ Results in the present study demonstrate that Chinese doctors extensively suffer WPV from patients or their relatives. However, compared with the previous literature, this study specially contributes to the understanding of the types of WPV. Made difficulties, smear reputation and mobbing behaviour were proposed first in this study, and it verified that the three new styles of violence defined in our study appeared to be more common than physical violence in hospital settings. Their respective incidence rates were $58.3 \%$ ( $\operatorname{rank} 2$ ), $40.8 \%$ (rank 3) and 40.2\% (rank 4). Additionally, the incidence rate of physical violence and sexual harassment was $24.1 \%$ and $7.8 \%$, respectively. Indeed, physical violence must inflict greater harm on the doctors, but the type of widespread violence found in this study is more likely to harm healthcare staff continually.
The adverse effects of WPV against doctors and the partial mediatory effects of psychological stress

As its name implies, WPV threatens the well-being of doctors, which we have demonstrated in our findings. Consistent with previous observations, ${ }^{38}$ exposure to WPV had a negative influence on Chinese doctors' subjective sleep quality and health status. There is reciprocal causation between the doctor-patient relationship and violence towards doctors. ${ }^{2}$ Although previous literature has discussed numerous causes of WPV and specially their unique characteristics in China, it is not the focus of our discussion. ${ }^{39}$ However, it is undeniably true that the level of tension in the doctor-patient relationship has further intensified following the increase of WPV. ${ }^{19}{ }^{40}$ It is incredible to see that some Chinese netizens unexpectedly support these violent events ${ }^{41}$ and a gradual formation of hatred towards doctors among Chinese patients; thus, the doctor-patient relationship has reached an unprecedentedly poor condition. Under these circumstances, Chinese doctors tend to specifically allocate much of their attention in dealing with the doctor-patient relationship, in order to protect themselves against violence from patients or patients' relatives. Therefore, doctors need to carefully express every word and input more 'emotional labour ${ }^{42}$ when they directly face the patient or relatives to avoid the complain. In order to avoid exposure to WPV, Chinese doctors are prone to invest more resources such as extra time and energy in dealing with the doctorpatient relationship. ${ }^{43}$ On the one hand, the resource investment represents the accumulative job demands of a doctor; on the other hand, they suffer from the patient's violence. In this case, two aspects may trigger feelings of distress and outrage in a doctor. It is an inequitable cost-reward evaluation of a doctor's professional and emotional investment, resulting in a process of resource depletion for the doctor. This state of resource depletion is closely related to stress, burnout and depression. ${ }^{44}$ More than that, a large number of previous studies have shown that effort-reward imbalance can lead to adverse health outcomes. ${ }^{45}{ }^{46}$ Several longitudinal studies had proved that the relationship between violence and stress is circular: violence causes stress and stressed workers are prone to exposure to violence. ${ }^{47}{ }^{48}$ Psychological stress caused by exposure to WPV is more likely to further lead to sleep disturbance and health damage for a doctor. It is an innovative contribution to research on exposure to WPV in a medical setting.

Table 4 Means (M), SDs and correlations of variables

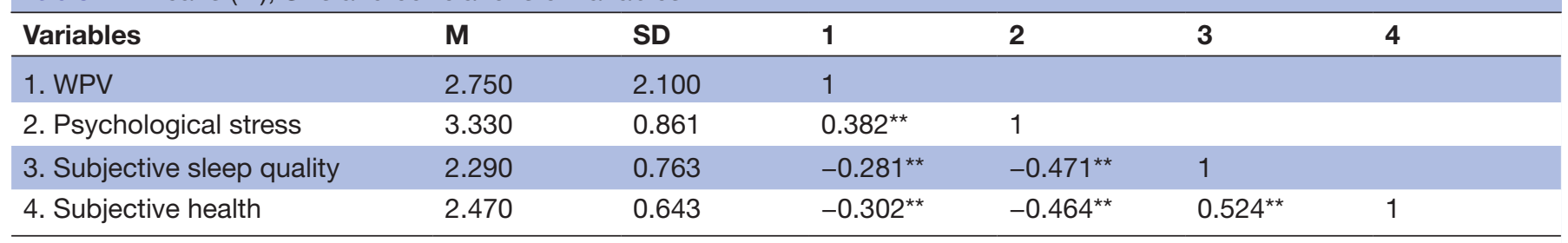

${ }^{\star *} \mathrm{p}<0.01$

WPV, workplace violence. 


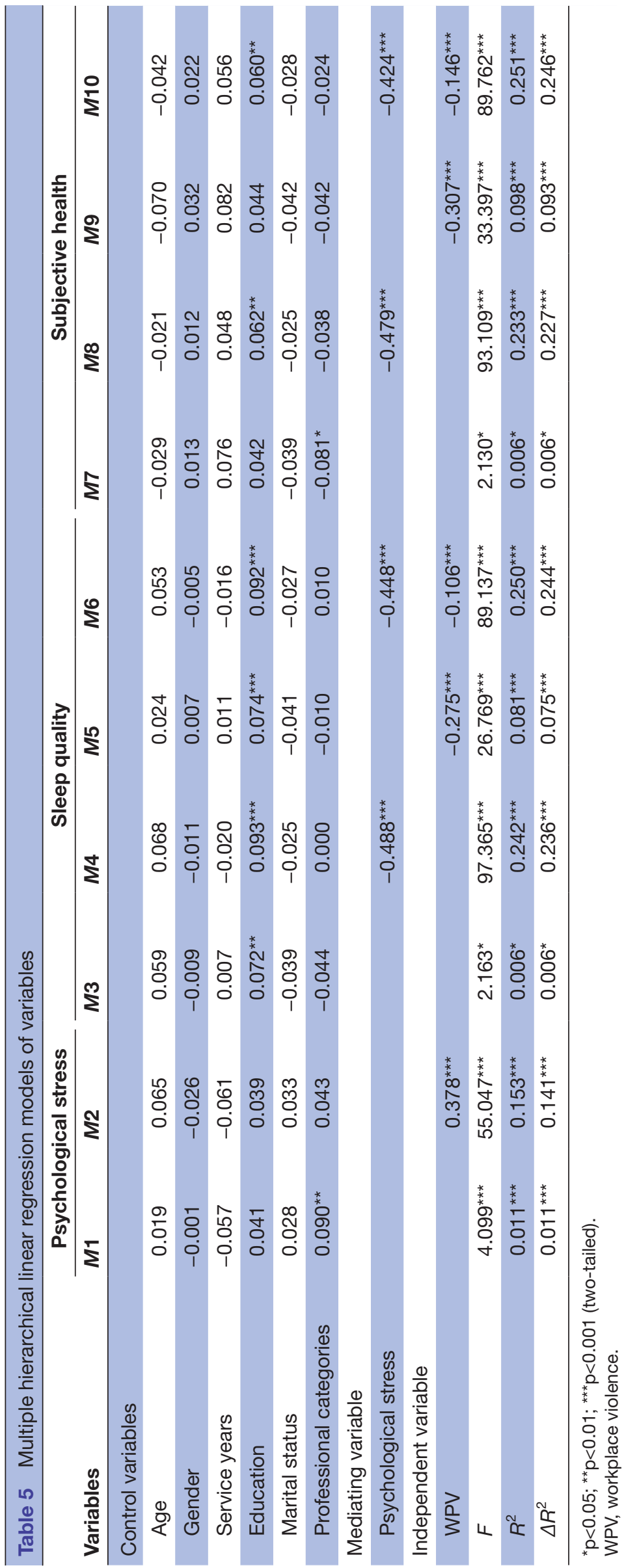

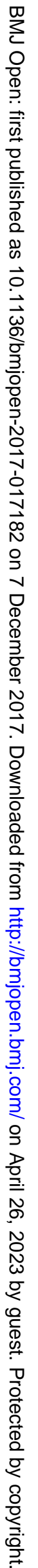




\section{Limitations}

Although there are significant discoveries in the present study, it has several limitations. First, a convenient sample was used, which risks the potential for sampling bias. Second, its cross-sectional nature prevented the establishment of a causal relationship between variables. Therefore, one important suggestion is that longitudinal studies should be conducted in the future. Third, the data were collected from the self-reports of doctors in an online survey, which may have led to response bias due to social desirability or negative effect. The doctors might have overestimated or underestimated the association between the study variables. Fourth, a specifically developed measurement tool using the Chinese validation has a great limitation. The validity of tool in this study need to further test. The choice to measure psychological stress, sleep quality and subjective health with one or two items weakens the assessment and shortens the validity of the measure tools. Fifth, a convenient sample was used in our study, which is very small compared to the Chinese doctors population. Moreover, due to the online survey for collecting data, the quality of the questionnaires not be monitored. Therefore, a rigorous sampling technique and a larger samples are needed in future research.

The samples in this study were large; however, these doctors were a small number of Chinese doctors. Moreover, considering of the sampling characteristics, the results of the study are not generalisable to all Chinese doctors.

\section{CONCLUSIONS}

The findings indicate that $83.4 \%$ of participants reported that they had suffered more than one type of WPV. Exposure to WPV towards Chinese doctors is common. All the seven styles of WPV were found among Chinese doctors. The incidence rate of violence from high to low are verbal abuse, made difficulties, smear reputation, mobbing behaviour, menace behaviour, physical violence and sexual harassment. This study also demonstrated that WPV was associated with psychological stress, sleep quality and subjective health. Finally, this study made a new discovery regarding a rarely mentioned variable in the previous literature; psychological stress played a mediating role in the relationship between exposure to violence and health damage.

Acknowledgements The authors would like to give their sincere thanks to all participants who had helped collect data and distribute questionnaires to other subjects.

Contributors Conceived and designed the study: $T S, L G$ and $F L$ designed this study ; TS, LG and FL drafted the manuscript; YS, FX, JW, SW, SZ collected data and controlled quality; WL, XD, XL, ZZ, LL and LF conducted the data analyses. All authors contributed to publishing the final manuscript.

Funding This study was funded by the Innovation Science Research Foundation of Harbin Medical University (2016RWZX09) to TS and also was funded by the Natural Science Foundation of China (71473063) to LF.

Competing interests None declared.

Patient consent Guardian consent obtained.
Ethics approval This study was approved by the ethics committee of the College of Public Health, Harbin Medical University. Due to the anonymous survey approach, the written informed consent could not be received; therefore, oral informed consent for survey was approved by the Ethics Committee of Harbin Medical University and obtained from each participant.

Provenance and peer review Not commissioned; externally peer reviewed.

Data sharing statement No additional data are available.

Open Access This is an Open Access article distributed in accordance with the Creative Commons Attribution Non Commercial (CC BY-NC 4.0) license, which permits others to distribute, remix, adapt, build upon this work non-commercially, and license their derivative works on different terms, provided the original work is properly cited and the use is non-commercial. See: http://creativecommons.org/ licenses/by-nc/4.0/

(c) Article author(s) (or their employer(s) unless otherwise stated in the text of the article) 2017. All rights reserved. No commercial use is permitted unless otherwise expressly granted.

\section{REFERENCES}

1. Meng Q. An interim interdisciplinary evaluation of China's national health care reform: emerging evidence and new perspectives. $J$ Asian Public Policy 2015;8:1-18.

2. Jing $W$, Otten $H$, Sullivan L, et al. Improving the doctor-patient relationship in China: the role of balint groups. Int $J$ Psychiatry Med 2013;46:417-27.

3. Anand S, Fan VY, Zhang J, et al. China's human resources for health: quantity, quality, and distribution. Lancet 2008;372:1774-81.

4. Feng Y, Li S, Wu Z. The study of the rational allocation of China's human resources for Health. Stud Soc Sci 2014;1:100-6.

5. Li Y, Wu Q, Liu C, et al. Catastrophic health expenditure and rural household impoverishment in China: what role does the new cooperative health insurance scheme play? PLoS One 2014;9:e93253.

6. Guo-zheng L, Zhen-jian Z, Cai-hui M, et al. Investigation and analysis of clinical doctors' humanity quality. Chin Hospi Manage 2012;32:17-19.

7. Shi J, Jiang $\mathrm{Y}, \mathrm{Hu} \mathrm{P}$, et al. A surveying study on social satisfaction to current doctor-patient relationship in China. JSSM 2015;08:695-702.

8. Ran L, Shuang X, Lu W. Analysis of 1645 cases irrational outpatient Chinese medicine prescriptions intervention. China Med Her 2014;11:154-8.

9. Pan Y, Yang Xhong, He JP, et al. To be or not to be a doctor, that is the question: a review of serious incidents of violence against doctors in China from 2003-2013. J Public Health 2015;23:111-6.

10. Lu-lu S, Shu-juan Y, Sen L, et al. Research of game relationship between hospitals and the media in doctor-patient disputes. Chin Hospi Manage 2014;34:66-8.

11. Shi J, Wang S, Zhou P, et al. The frequency of patient-initiated violence and its psychological impact on physicians in china: a cross-sectional study. PLoS One 2015;10:e0128394.

12. Belayachi J, Berrechid K, Amlaiky F, et al. Violence toward physicians in emergency departments of Morocco: prevalence, predictive factors, and psychological impact. J Occup Med Toxicol 2010;5:1-7.

13. Saines JC. Violence and aggression in A \& E: recommendations for action. Accid Emerg Nurs 1999;7:8-12.

14. AL Bashtawy M, Aljezawi M. Emergency nurses' perspective of workplace violence in Jordanian hospitals: a national survey. Int Emerg Nurs 2016;24:61-5.

15. Yao S, Zeng Q, Peng M, et al. Stop violence against medical workers in China. J Thorac Dis 2014;6:141-5.

16. Lancet. Violence against doctors: why China? Why now? What next? Lancet 2014;383:1013.

17. Phillips JP. Workplace violence against health care workers in the United States. N Engl J Med 2016;374:1661-9.

18. Ze-lin Y, Hao-yue Z, Si-jia L. Right-protection by Violence in Healthcare Service and Its Governance: Based on Content Analysis of News Reports from 2002 to 2015. Soc Constr 2017;4:49-63.

19. Ke Y, Wen-yu C, Ting Z, et al. Analysis of medical violence cases though the court trial and ruling Nearly five years in China. Chin Hospi Manage 2016;36:68-70.

20. Mirza NM, Amjad Al, Bhatti AB, et al. Violence and abuse faced by junior physicians in the emergency department from patients and their caretakers: a nationwide study from Pakistan. J Emerg Med 2012;42:727-33.

21. Heponiemi T, Kouvonen A, Virtanen M, et al. The prospective effects of workplace violence on physicians' job satisfaction and turnover 
intentions: the buffering effect of job control. BMC Health Serv Res 2014;14:19.

22. Hanson GC, Perrin NA, Moss $\mathrm{H}$, et al. Workplace violence against homecare workers and its relationship with workers health outcomes: a cross-sectional study. BMC Public Health 2015;15:11.

23. Lin WQ, Wu J, Yuan LX, et al. Workplace violence and job performance among community healthcare Workers in China: the mediator role of quality of life. Int J Environ Res Public Health 2015;12:14872-86.

24. Kivimäki M, Virtanen M, Vartia $M$, et al. Workplace bullying and the risk of cardiovascular disease and depression. Occup Environ Med 2003;60:779-83.

25. Carmi-Iluz T, Peleg R, Freud T, et al. Verbal and physical violence towards hospital- and community-based physicians in the Negev: an observational study. BMC Health Serv Res 2005;5:1-6.

26. Wu S, Zhu W, Li H, et al. Workplace violence and influencing factors among medical professionals in China. Am J Ind Med 2012;55:1000-8.

27. Xing $\mathrm{K}$, Zhang $\mathrm{X}$, Jiao $\mathrm{M}$, et al. Concern about workplace violence and its risk factors in Chinese township hospitals: a cross-sectional study. Int J Environ Res Public Health 2016;13:811.

28. World Health Organization. Violence: a public health priority. Geneva, Switzerland, 1996.

29. Magnavita N, Heponiemi T. Workplace violence against nursing students and nurses: an Italian experience. J Nurs Scholarsh 2011:43:203-10.

30. Magnavita N, Heponiemi T. Violence towards health care workers in a Public Health Care Facility in Italy: a repeated cross-sectional study. BMC Health Serv Res 2012;12:108.

31. Ding Z, Dan L, Yu S, et al. Impact of patients violence in public hospital on job burnout of nurses. Chin Hospi Manage 2016;36:69-71.

32. Buysse DJ, Reynolds CF, Monk TH, et al. The Pittsburgh Sleep Quality Index: a new instrument for psychiatric practice and research. Psychiatry Res 1989;28:193-213.

33. Fein EC, Skinner N. Clarifying the effect of work hours on health through work-life conflict. Asia Pac J Hum Resour 2015;53:448-70.

34. Baron RM, Kenny DA. The moderator-mediator variable distinction in social psychological research: conceptual, strategic, and statistical considerations. J Pers Soc Psychol 1986;51:1173-82.
35. Preacher KJ, Hayes AF. Asymptotic and resampling strategies for assessing and comparing indirect effects in multiple mediator models. Behav Res Methods 2008;40:879-91.

36. Shi J, Wang S, Zhou P, et al. The frequency of patient-initiated violence and its psychological impact on physicians in China: a cross-sectional study. PLoS One 2015;10:e0128394.

37. Liu H, Zhao S, Jiao M, et al. Extent, nature and risk factors of workplace violence in public tertiary hospitals in China: a crosssectional survey. Int J Environ Res Public Health 2015;12:6801-17.

38. Wu S, Lin S, Li H, et al. A study on workplace violence and its effect on quality of life among medical professionals in China. Arch Environ Occup Health 2014;69:81-8.

39. Yifu R, Lihua F, Shaoxing S, et al. Qualitative research on workplace violence events in public hospitals in heilongjiang province. Med Society 2016;29:10-788.

40. Ze-lin Y, Hao-yue Z, Si-jia L. Right-protection by Violence in Healthcare Service and Its Governance:based on content analysis of news reports from 2002 to 2015. Soc Constr 2017:4:49-63.

41. Qin X, Yin W, Huang D, et al. Social psychological analysis and implications of internet public opinion on hospital violence. Chin Med Ethics 2015;28:21-5.

42. Ashforth BE, Humphrey RH. Emotional labor in service roles: the influence of identity. Acad Manage Rev 1993;18:88-115.

43. Hobfoll SE. Stress, culture, and community: the psychology and philosophy of stress. Br J Med Psychol 1998;44:408-9.

44. Neveu JP. Jailed resources: conservation of resources theory as applied to burnout among prison guards. J Organ Behav 2007;28:21-42.

45. Smith LA, Roman A, Dollard MF, et al. Effort-reward imbalance at work: the effects of work stress on anger and cardiovascular disease symptoms in a community sample. Stress Health 2005;21:113-28.

46. Ota A, Mase J, Howteerakul N, et al. The effort-reward imbalance work-stress model and daytime salivary cortisol and dehydroepiandrosterone (DHEA) among Japanese women. Sci Rep 2014;4:6402-02.

47. Magnavita N. The exploding spark: workplace violence in an infectious disease hospital-a longitudinal study. Biomed Res Int 2013;2013:247-61

48. Magnavita N. Workplace violence and occupational stress in healthcare workers: a chicken-and-egg situation-results of a 6-year follow-up study. J Nurs Scholarsh 2014;46:366-76. 